\title{
Schools Teachers' Experiences of Social Network Sites in Relation to Improving the Skills of Arabic Language Acquisition: Impact, Strengths, and Weaknesses
}

\author{
Mustafa Jwaifell ${ }^{1}$, Reema Abu-Omar ${ }^{2}$ \& Mahmoud BaniAbdel-Rahman ${ }^{3}$
}

1Professor, Instructional Technology, Faculty of Education, Al-Hussein Bin Talal University, Jordan, https://orcid.org/0000-0002-7279-7253

${ }^{2}$ Associate Professor, Faculty of Education, Al-Hussein Bin Talal University, Jordan

${ }^{3}$ Professor, TEF Faculty of Education, Al-Hussein Bin Talal University, Jordan

Correspondence: Mustafa Jwaifell, Professor, Instructional Technology, Faculty of Education, Al-Hussein Bin, Talal University, Jordan.

Received: June 262020

Accepted: July 17, 2020

Online Published: July 21, 2020

doi:10.5430/ijhe.v9n5p153

URL: https://doi.org/10.5430/ijhe.v9n5p153

\begin{abstract}
This paper investigates elementary and secondary teachers' experiences of the impact, strength, and weaknesses of Social Network Sites (SNS) with regard to improving students' acquisition of Arabic Language. The study sample consisted of (85) Arabic language teachers; (77) of them responded to a questionnaire that measured their experiences of SNS's impact, strengths, and weaknesses. The researchers used descriptive statistics, ANOVA and T-test. The data analyses revealed an existent of impact, strengths, and weaknesses of SNS on elementary and secondary students' acquisition of Arabic Language. The study recommended the focus on overcoming weaknesses and taking advantage of using SNS in learning environments.
\end{abstract}

Keywords: SNS impact, SNS strengths, SNS weaknesses, Arabic language skills

\section{Introduction}

While digital technologies invaded all fields of life including education, conduct, work and ways living, -depending on smart phones and internet usage, along with the spread of using Social Networks Sites (SNS) among teenagers; students need to understand how to take advantage of SNS to achieve their own personal and academic goals. Academics and policy makers are committed to assure that SNS will not affect the language as an essential heritage of any country, and at the same time, make use of SNS to enhance teaching and learning processes through integrating SNSs within learning and teaching environments or even giving teachers attention to exploit relative advantages of SNSs academically and implement new innovations of methodologies such as Mobile learning or interact with students through Internets' technologies. While teachers experiences may shed the light on how SNSs may affect their students acquisition of Arabic Language, the nature of such culture of a small city like Ma'an in the southern part of Jordan is very close in different way to teachers' students even the type of their relationship with their students is based on many considerations where the concept of one tripe is very essential in this community.

\section{Background of the Study}

Teaching Arabic Language during different learning levels aims at enhancing the students' essential skills of reading, writing, speaking, and listening. It also helps them acquire different terminology, expressions, thoughts, and meanings that are necessary for their everyday-life communication and interaction. The importance of language appears in its being considered as a tool to gain knowledge and different experiences. Moreover, it is one of the significant methods for accomplishing school tasks since language is a key communicational means between the student and the surrounding environment. Therefore, Arabic language is not a mere study course only; it is also a means to study other courses. As a result, Arabic language curriculum is not an aim in itself, rather it is a means to achieve a certain purpose; modifying the students' linguistic behavior through their interaction with experiences and the linguistic activities included in the curriculum. 
Reading is an essential linguistic skill which basically comes after listening and speaking skills. It is described as a mental physiological process through which the reader recognizes written symbols, pronounce them, understand their meanings, and connect between the meanings of these symbols and his experiences, meanings, and indications.

Writing is also one of the communicational means by which a student can express his/her thoughts, criticize others' thoughts, highlight his concepts and emotions, and record whatever incidents and realities he wishes to keep. One's handwriting could be a reason in changing the meaning and bringing an ambiguous idea to the reader. Therefore, proper writing is considered as an important process in education since it is an essential factor of culture and a social necessity to transfer ideas.

Arabic language curricula pay great attention to improving writing skill as one of the necessary and important linguistic skills. Unfortunately, it is observed that school as well as university graduates do not write properly. In fact, they make many linguistic and spelling mistakes don't pay attention to punctuation marks, and their ideas do not flow cohesively or coherently.

Many studies and researches, such as Abu Omar (2014) showed students' weakness in writing or in writing composition. Their weakness appears in their inability to concentrate on the central idea of the subject matter in addition to their misuse of conjunctions. With regard to content, students do not follow standard language as well as spelling and linguistic structures which weakens their writing style. As for form, they neglect the significance of indentation and classifying ideas into paragraphs, in addition to their ignorance in using punctuation marks correctly. Besides, they have illegible handwriting that prevents understanding.

In the meantime, Arabic language faces different challenges, not the least of which is the spread of colloquial language and the intervention of other foreign languages used in communication, press, and the different social media. Thus, it is crucial here that people shed light on using standard Arabic and developing the four communicational skills: listening speaking, reading, and writing. In so doing, certain objectives can be accomplished; such as providing students with cognitive and linguistic richness; using students' mental abilities to understand, develop, analyze, conclude, and criticize; and teaching them good speaking habits characterized by fluency and adequate cognitive credit that help them through different fields of life (The Ministry of Education, 2013).

Nowadays, some new ways (i.e. 'textese') that are unfamiliar to Arabic language writing are being used in social-media websites. 'Textese' is a chat language that uses abbreviated syllables like LOL $=$ laughing. It is also known as 'txt-speak,' 'chats-peak,' 'text-ling,' and other names. It also happens that certain numbers that are phonetically synonymous with English letters or syllables can be used in chatting, like gr8 = great; or reducing the number of letters, like cuz=because; even punctuations are used to express feelings, like :(= sadness (Drouin, 2011: $67)$.

This new phenomenon of writing has influenced chatting in Arabic language on social-media websites. Known as "Arabizi" or 'Franco-Arab' is a system of writing Arabic in English that teenagers use where they also mix numbers that represent some Arabic letters. Here are some examples:

Table 1. Examples of Arabizi

\begin{tabular}{|c|c|c|c|}
\hline English Meaning & pronunciation & Arabizi & Arabic Word \\
\hline Came & Ja'a & $\mathrm{Ja} 2$ & جاء اء \\
\hline Work & Amal & 3amal & عطل \\
\hline Strange & Ghareeb & 3'areeb & غريب \\
\hline Constance & Thabet & 4abet & تئابث \\
\hline News & Khabar & $5 \mathrm{abar}$ & خبز \\
\hline Bird & Ta'er & $6 a 2 r$ & طائر \\
\hline Said & Kal & $8 \mathrm{al}$ & 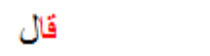 \\
\hline
\end{tabular}




\begin{tabular}{|c|c|c|c|}
\hline Dream & Holom & 7olom & حلم \\
\hline Sound & Sawt & 9awt & صوت \\
\hline Peace Upon you & Assalamo alaykom, $\mathrm{A}=3$ & ISA & السلآم عليكم \\
\hline If God so well & In sha'a Allah & Insha2a Allah & إن شَاء الله \\
\hline
\end{tabular}

SNSs can be described as a virtual community where people with common interest may meet. Beside this description, scholars defined SNS as an individual web page which enables online human-relationship building by collecting useful information and sharing it with specific or unspecific people (Kwon and Wen, 2009). Whereas Boyed and Ellison (2007) defined SNS as web-based services that allow individuals to construct a public or semi-public profile within a bounded system. In Jordan, for example, the use of Facebook is part of the university students' everyday activity (Bsharah, Gasaymeh, and Bani Abdelrahman, 2014); While SNS has an academic use as Al Doghmi, A., Al-Shalabi, H., Jwaifell,M. , Andraws, S., Awajan, A., \& Alrabea, A. I.(2013) stated.

\section{Related Studies}

Teaching There are few studies related to the SNS concerning its impact, strengths, and weaknesses on Arabic language, especially those measuring teachers' experiences for using SNS like the studies of Al-Sarhan (2012), Bazarah (2016), and $\mathrm{Al}$ omosh (2018).

Al-Sarhan (2012) studied internet usage in teaching among male and female teachers in secondary schools in Mafraq governorate. The study sample consisted of (160) Arabic Language teachers. Data were collected by a questionnaire. The results revealed that the level of internet usage was intermediate; teachers' attitudes toward using the internet in teaching Arabic Language were highly positive, and the obstacles hindered the usage of internet in teaching were medium, while technical and financial obstacles were high.

Bazarah (2016) study aimed at identifying the relationship between the social Network sites (SNS) and Arabic language skills acquisition among high school students from the perspective of Arabic language teachers. The study sample consisted of (218) Arabic female teachers of the Riyadh secondary schools. The study results showed statistically significant differences between the teachers' point of view mean and the crucial score (3) for the benefit of SNS in Arabic language acquisition. Whereas independent samples t-test showed that there is no statistically significant difference between the teachers' point of view with regard to the educational system that teachers follow. ANOVA also showed no significant differences according to teachers' experiences. Also, the results of One sample t-test showed statistically significant differences between the teachers' point of view mean and the crucial score (3) for the disadvantages in SNS that weaken Arabic language acquisition. Independent samples t-test showed that there is a statistically significant difference between the teachers' point of view with regard to the educational system that teachers follow. Whereas, ANOVA showed no significant differences according to teachers' experiences.

The recent study of $\mathrm{Al}$ omosh (2018) aimed at identifying the use of Arabic language teachers in the implementation of class activities. The study sample consisted of (270) teachers who teach the Arabic language in the schools Al-Mafraq. The study results indicated that teachers of Arabic language use extracurricular activities in a medium degree, and the reasons for the use of school broadcasting and school press are very high. The results also showed that there were differences of statistical significance at the level of $(\alpha=0.05)$ due to the effect of sex in all fields and in the total score. The differences were in favor of females. The study recommended that extra-curricular activities must be given more patronage and attention.

Arabic language skills get affected in a way or another by the use of social-media websites. Consequently, the need for studying how positive or negative this influence is on students' Arabic-language skills has appeared. Therefore, the study in hand aims at exploring Teachers' Experiences of Social Network Sites in Relation to Improving Language Acquisition: Impact, Strengths, and Weaknesses.

\section{Rational of the Study and Research Questions}

The students' uses of SNSs may differ according to their needs; personal uses or academic uses. Meanwhile, teachers' experiences may provide a clear picture of these uses and what changes or development they bring to the students' language. Therefore, this study aimed at determining the impact, strengths, and weaknesses of SNS in relation to improving Arabic Language skills acquisition by answering the following questions: 
1. What is the impact degree of SNS in improving Arabic Language acquisition for the students of higher elementary and secondary stages based on their teachers' experiences?

2. What are the strengths of SNS which improve Arabic Language acquisition for the students of higher elementary and secondary stages based on their teachers' experiences?

3. What are the weaknesses of SNS which prevent improving Arabic Language acquisition for the students of higher elementary and secondary stages based on their teachers' experiences?

\section{Method}

The study adopted a descriptive research design. The researchers conducted a survey through using a measurement tool for collecting data on the Teachers' Experiences of SNS in relation to improving Arabic Language skills acquisition: Impact, Strengths, and Weaknesses; in order to have a clear picture through teachers' experiences if SNS helped in improving the acquisition of Arabic Language of their students, and if it has advantages or weaknesses that strengthenlweaken the students' acquisition of Arabic Language by navigating or interacting through SNS. The judgment of teachers' experience about their students is very acceptable for the researchers in a community such as Ma'an because most of the teachers are from the same tripe and culture of Ma'an and they have strong relationships with the students' families alongside their interaction with their students while teaching Arabic Language in class.

\subsection{The Study Population and Sample}

The sample of this study consisted of all Arabic language teachers in Ma'an Directorate who teach Eight - 12K grades. All $(100 \%)$ population of the study is the sample itself (male=43/female=42). Only $(77)$ of the questionnaires were returned or were valid to be analyzed, as shown in Table 2:

Table 2. The study population and its sample

\begin{tabular}{llllllll}
\hline Years of experience & Class & Gender & & & \multicolumn{3}{c}{ Total } \\
& & Male & & Female & \\
& & Population & Sample & Population & Sample & Population & Sample \\
\hline $\mathbf{1 - 5}$ & Elementary & 9 & 8 & 10 & 10 & 19 & 18 \\
& Secondary & 6 & 4 & 4 & 3 & 10 & 7 \\
& Total & 15 & 12 & 14 & 13 & 29 & 25 \\
$\mathbf{6 - 1 0}$ & Elementary & 8 & 7 & 4 & 2 & 12 & 24 \\
& Secondary & 7 & 7 & 10 & 10 & 17 & 17 \\
\multirow{4}{*}{ More Than 10 } & Total & 15 & 14 & 14 & 12 & 29 & 26 \\
& Elementary & 8 & 7 & 4 & 2 & 12 & 24 \\
& Secondary & 7 & 7 & 10 & 10 & 17 & 17 \\
Totals & Total & 15 & 14 & 14 & 12 & 29 & 26 \\
& Elementary & 23 & 21 & 22 & 20 & 45 & 41 \\
& Secondary & 20 & 17 & 20 & 19 & 40 & 36 \\
& Total & 43 & 38 & 42 & 39 & 85 & 77 \\
\hline
\end{tabular}

Only nine female teachers hold Master or PhD degrees, while (30) of them hold BSC degrees. On the other hand, (12) male teachers hold Master or PhD degrees, while (26) of them hold BSC degrees. Teachers have been engaged in many workshops about teaching methodologies before working in schools as teachers. They also have a better understanding of SNSs since all of them have at least a Facebook account. Therefore, they have a good understanding of its uses.

The researchers' main concern was to measure the impact, strengths, and weaknesses of SNSs in acquiring Arabic Language skills for both elementary and secondary students in order to understand the whole picture of their experiences and give recommendations to universities and the administration of Ministry of Education in Jordan to gain a better understanding when planning for teachers' training and pre-service training. 


\subsection{Ethical Considerations}

The study was approved by Al-Hussein Bin Talal University Research Ethics Committee at the Faculty of Education and approved by the Directorate of Education for the Governorate of Ma'an. All participants were treated as anonymous by asking them not to mention or write their names or signatures on the questionnaire.

\subsection{Data Collection Method}

Data of the study questions were derived by surveying the point view of (77) Arabic Language teachers in Ma'an directorate and were analyzed in a way to protect the confidentiality of all the participants by giving them pseudonyms.

\subsection{The Study Tool}

The study measurement tool was based on Bazarah's study (2016) which used the tool for measuring the relationship between SNS and Arabic Language skills acquisition among secondary stage female students from Arabic Language teachers' point view. The researchers developed the measurement tool for the purposes of the study since the core of Arabic Language skills is the same for students of 8-12 grades. When analysing the content items, it appeared to the researchers and the 6 referees that those items did not have any cultural biases and commonly applicable to Ma'an directorate teachers in Jordan as within Middle Eastern context. The measurement tool consisted of four parts:

1. Demographic description of the sample,

2. Impact of SNS on improving the Arabic Language skills acquisition of listening, speaking, reading, and writing,

3. Strengths (advantages) of SNS that improve Arabic Language skills acquisition. This part consisted of seven items reflecting the advantages available in SNS that strengthen the improvement of Arabic Language acquisition:

- Arabic Sites: Availability of SNSs that serve in presenting information and knowledge about Arabic Language.

- Classical Language: Availability of famous scientists, authors, and writers who speak and write in classical Arabic Language at SNSs.

- Writing Tools: Availability of tools in the SNSs for encouraging any user to practice writing and publishing on those sites.

- Multimedia: Availability of written texts recorded that can be listened to in classical Arabic Language.

- Reading Activities: Availability of pages and accounts in SNSs that encourage reading through different activities and ways.

- Original Resources: Availability of learning resources and content suitable for Arabic Language.

- Virtual Reality: Availability of opportunities in SNSs to practice the for skills (reading, writing, listening, and speaking) of Arabic Language.

4. Weaknesses of SNS that affect improving Arabic Language skills acquisition. This part consisted of (11) items reflecting the disadvantages of SNS that weaken the improvement of Arabic Language acquisition:

- Colloquial Language: The prevalence of colloquial language in SNSs.

- b) Arabezee: The prevalence of Arabized English using English letters and numbers in writing.

- Mixed Languages: Mixing between Arabic and other foreign languages.

- Weak Partners: Communicating with partners whose language skills are weak.

- Common Writing: The desire to get along with the society's way of writing.

- Spelling Mistakes: The spread of spelling and linguistic mistakes in SNS.

- Grammatical Mistakes: The spread of grammatical mistakes in texts at SNS.

- Editing Responsibly: The lack of correcting, editing, or revising processes for SNS.

- Electronic Writing: Using keyboards for typing instead of writing weakens students' Arabic handwriting skills.

- Eloquence vs. Intellectuality: Some scripts are linguistically eloquent but intellectually weak.

- Attention Distraction: SNSs distract students from what is useful and waste their time.

The developed version was validated by 6 referees of Al-Hussein Bin Talal University instructors who hold PhD degrees in Instructional Technology, Information Technology, Curriculum and Instruction, Statistics and two of Arabic Language supervisors in Ma'an Directorate. The reliability of the questionnaire was calculated using Cronbach's Alpha Coefficient, as shown in Table 3: 
Table 3. Reliability of the questionnaire and its domains

\begin{tabular}{lllll}
\hline Domain & Improving skills & $\mathrm{N}$ of items & Cronbach's alpha & Pearson correlation \\
\hline Impact on improving & Listening & 4 & 0.858 & $0.791^{* *}$ \\
& Speaking & 13 & 0.921 & $0.918^{* *}$ \\
& Reading & 7 & 0.795 & $0.853^{* *}$ \\
& Writing & 6 & 0.909 & $0.888^{* *}$ \\
Total impact on improving & 30 & 0.951 & \\
Strengths & 7 & 0.789 & \\
Weaknesses & 11 & 0.880 & \\
\hline
\end{tabular}

** Correlation is significant at the 0.01 level (2-tailed)

Measurement scale of the tool was transformed into five levels of impact, strength, and weakness as shown in table 4:

Table 4. Scaling impact, strengths, and weakness degree

\begin{tabular}{lllll}
\hline Very Low & Low & Medium & High & Very high \\
\hline 1 & 2 & 3 & 4 & 5 \\
$1-1.80$ & $1.81-2.60$ & $2.61-3.40$ & $3.41-4.20$ & $4.21-5$ \\
\hline
\end{tabular}

\subsection{Data Analyses}

Data obtained from the questionnaire were analyzed using SPSS. The collected ratio data were classified and analyzed to answer the study question. Hence the classified variables have one, two or three levels, and different types of statistical procedures were used: one sample t-test was used to answer the first question, two-sample t-test for the second question, and One-way ANOVA and Scheffe's multiple comparison test for answering the third question.

\section{Findings and Discussion}

The analysis of the resulting ratio data was performed using descriptive statistics. Descriptive measures including means and standard deviations for Impact domains, strengths, and weaknesses were calculated to answer the study questions. These descriptive statistical measures were also tabulated and reported for classifying the variables (qualification, Grades, gender, and years of experience) to determine the teachers' experiences in SNS improvement of Arabic Language Acquisition. Results according to questions of the study were as follows:

Question 1: What is the impact degree of SNS on improving Arabic Language acquisition for the students of higher and secondary stages based on their teachers' experience?

The analysis of One sample t-test with $(\mathrm{df}=76)$ were used to determine the impact of SNS on improving Arabic Language acquisition at the crucial score of upper bound of impact degree (see Table 4):

Table 5. Results of one sample t-test for the impact of SNS

\begin{tabular}{llllllll}
\hline Skills & Mean & SD & Improving degree & Crucial score & T value & Sig & Improving degree \\
\hline Listening & 3.55 & 0.85 & High & 3.40 & 1.496 & .139 & Medium \\
Speaking & 3.72 & 0.71 & & & 3.919 & $.000(\mathrm{a})$ & High \\
Reading & 3.47 & 0.91 & & & 0.671 & .504 & Medium \\
Writing & 3.49 & 0.89 & & & 0.897 & .373 & Medium \\
Improvement & 3.59 & 0.71 & High & 3.40 & 2.363 & .021 & High
\end{tabular}

One sample t-test revealed that there aren't significant differences at $\alpha \leq 0.05$ between the mean of Listening (3.55), Reading (3.47), and Writing (3.49) and the crucial score (3.40) which represents the upper bound of Medium degree. Thus, the impact of SNS on improving these skills is medium. On the contrary, there are significant differences between the means of (Speaking and the total of skills improvement) and the crucial score (3.40) which represents the upper bound of High degree. Thus, the SNS impact on improving Arabic Language skills acquisition of speaking and the total degree based on the teachers' experiences is high, which shows a high intensity of using social networks among students as revealed in the study of Jwaifell, M., Al-Shalabi, H., Andraws, S., Awajan, A., \& Alrabea, A. (2013). 
Two sample t-test was used to determine the impact of SNS on improving Arabic Language acquisition according to teachers' experience in relation to variables: Gender of students, Stage and Qualification of teachers as shown in Table 6:

Table 6. Resutls of two sample t-test for (DF=75) the impact of SNS

\begin{tabular}{|c|c|c|c|c|c|c|c|}
\hline \multirow[t]{2}{*}{ Domains } & & \multicolumn{2}{|l|}{ Gender } & \multicolumn{2}{|l|}{ Stage } & \multicolumn{2}{|c|}{ Qualification } \\
\hline & & $\begin{array}{l}\text { Mal. } \\
\mathrm{N}=38\end{array}$ & $\begin{array}{l}\text { Female. } \\
\mathrm{N}=39\end{array}$ & $\begin{array}{l}\text { Elementary. } \\
\mathrm{N}=41\end{array}$ & $\begin{array}{l}\text { Secondary. } \\
\mathrm{N}=36\end{array}$ & $\begin{array}{l}\text { BSC. } \\
\mathrm{N}=56\end{array}$ & $\begin{array}{l}\text { MasterlPhD. } \\
\mathrm{N}=21\end{array}$ \\
\hline \multirow[t]{4}{*}{ Listening } & Mean & 3.47 & 3.62 & 3.62 & 3.46 & 3.62 & 3.36 \\
\hline & SD & 0.71 & 0.97 & 0.87 & 0.84 & 0.87 & 0.80 \\
\hline & $\mathrm{T}$ & 0.793 & & 0.838 & & 1.189 & \\
\hline & Sig & 0.430 & & 0.405 & & 0.238 & \\
\hline \multirow[t]{4}{*}{ Speaking } & Mean & 3.69 & 3.75 & 4.00 & 3.40 & 3.77 & 3.58 \\
\hline & SD & 0.62 & 0.81 & 0.48 & 0.80 & 0.76 & 0.58 \\
\hline & $\mathrm{T}$ & 0.398 & & $4.001 * *$ & & 1.085 & \\
\hline & Sig & 0.692 & & $0.000(a)$ & & 0.281 & \\
\hline \multirow[t]{4}{*}{ Reading } & Mean & 3.30 & 3.63 & 3.67 & 3.25 & 3.54 & 3.29 \\
\hline & SD & 0.82 & 0.97 & 0.84 & 0.94 & 0.89 & 0.95 \\
\hline & $\mathrm{T}$ & 1.627 & & $2.067^{*}$ & & 1.089 & \\
\hline & Sig & 0.108 & & 0.042 & & 0.280 & \\
\hline \multirow[t]{4}{*}{ Writing } & Mean & 3.46 & 3.52 & 3.37 & 3.23 & 3.60 & 3.21 \\
\hline & SD & 0.89 & 0.91 & 0.82 & 0.91 & 0.88 & 0.88 \\
\hline & $\mathrm{T}$ & 0.225 & & $2.517^{*}$ & & 1.736 & \\
\hline & Sig & 0.800 & & 0.014 & & 0.087 & \\
\hline \multirow[t]{4}{*}{ Improvement } & Mean & 3.52 & 3.66 & 3.82 & 3.34 & 3.66 & 3.40 \\
\hline & SD & 0.61 & 0.81 & 0.59 & 0.76 & 0.73 & 0.63 \\
\hline & $\mathrm{T}$ & 0.81 & & $3.115^{*}$ & & 1.421 & \\
\hline & Sig & 0.402 & 0. & 003 & & 0.160 & \\
\hline
\end{tabular}

Out of Table 6, two sample t-test revealed:

1. According to teachers' experience, it appears that SNS improved male and female students of Arabic Language acquisition in a high degree except in Reading where Male in medium degree. Two sample t-test revealed that there are no significant differences at $(\alpha \leq 0.05)$ between Male and Female students according to teachers' experience in improving Arabic Language skills acquisition.

2. When comparing the SNS improvement degree in Arabic Language acquisition according to the stage (ElementarylSecondary) it appears that teachers' experience reported a high improvement in elementary stage for all Arabic Language skills and at the total of improvement, while secondary stage improvement was only in Listening with no significant differences between elementary and secondary stages in Listening, but t-test showed significant differences in Speaking, Reading, Writing, and the total of skills (Improvement) for the benefit of elementary stage students according to teachers' experiences.

3. Analysis of teachers' qualification showed that teachers experience according to their qualifications doesn't differ significantly in their view to SNS impact. While all teachers who hold BSC believe that SNS's impact can improve students' acquisition of Arabic Language skills in a high degree, teachers who hold $\mathrm{PhD}$ or Master degrees believe that SNS impact has a median dgree except in speaking it is high.

Those findings show that Arabic teachers believe that SNSs have a high degree of impact on improving the acquisition of Arabic Language skills according to their experience. Based on these results, it appears that the SNS 
can play a very important role in helping both students and teachers to take advantages of SNS and its' tools in communicating with each other, therefore, teachers can integrate SNS in teaching and learning situations.

To understand the teachers' years of experience differences in judging the impact of SNS on improving Arabic Language skills, two statistical methods were used: one-way ANOVA to measure differences according to teachers' years of experience and Pearson Correlation to explain this relation.

Table 7. Means and and atabdared deviation of SNS impact according teachers' years of experience

\begin{tabular}{lllllllll}
\hline Domains & \multicolumn{3}{l}{ 1-Years. N=25 } & \multicolumn{2}{l}{ 2-10 Years. N=26 } & \multicolumn{2}{l}{ 11Years and More. N=26 } & \multicolumn{2}{l}{ Total. N=77 } \\
& Mean & SD & Mean & SD & Mean & SD & Mean & SD \\
\hline Listening & 3.70 & 0.77 & 3.51 & 0.98 & 3.43 & 0.80 & 3.55 & 0.85 \\
Speaking & 3.99 & 0.51 & 3.77 & 0.72 & 3.41 & 0.78 & 3.72 & 0.71 \\
Reading & 3.87 & 0.58 & 3.40 & 1.07 & 3.15 & 0.87 & 3.47 & 0.91 \\
Writing & 3.87 & 0.68 & 3.40 & 0.99 & 3.22 & 0.88 & 3.49 & 0.89 \\
Improvement & 3.90 & 0.51 & 3.57 & 0.77 & 3.31 & 0.73 & 3.59 & 0.71
\end{tabular}

Table 7 shows the obvious means of SNS impact on improving Arabic Language skills according to teachers' years of experience. One-way ANOVA was conducted to examine the differences in those means as shown in Table 8:

Table 8. One-way ANOVA summery of SNS impact according to years of experience

\begin{tabular}{lllllll}
\hline Source of Variance & & Sum of squares & DF & Mean square & F & Sig \\
\hline Listening & Between groups & 0.961 & 2 & 0.481 & 0.654 & .523 \\
\multirow{5}{*}{ Speaking } & Within Groups & 54.380 & 74 & 0.753 & & \\
\multirow{5}{*}{ Reading } & Between groups & 4.457 & 2 & 2.228 & 4.795 & .011 \\
& Within Groups & 34.393 & 74 & .465 & & \\
Writing & Between groups & 6.829 & 2 & 3.414 & 4.530 & .014 \\
& Within Groups & 55.778 & 74 & 0.754 & & \\
Improvement & Between groups & 5.664 & 2 & 2.832 & \multirow{2}{*}{3.807} & .027 \\
& Within Groups & 55.052 & 74 & 0.744 & & \\
& Between groups & 4.409 & 2 & 2.205 & \multirow{2}{*}{4.756} & .011
\end{tabular}

Table 8: Results of the ANOVA revealed no significant differences at $\alpha \leq 0.05$ between the means of experience years with regard to the Listening skill, whereas there are significant differences between the means of experience years categories in Speaking, Reading and Writing skills and the overall of Arabic Language skills improvement. Thus, Arabic language teachers in Ma'an Directorate differ via their experiences regarding the impact of SNS on improving the acquisition of Arabic Language skills, except for Listening skill. Scheffe's Post multiple comparison was conducted to assure those differences as shown in Table 9:

Table 9. Results of Scheffe's multiple comparison

\begin{tabular}{llllll}
\hline Dependent variable & (I) Experience & $(\mathrm{J})$ Experience & $(\mathrm{I}-\mathrm{J})$ & Std. Error & Sig \\
\hline Speaking & From 1-5 & From 6-10 & .22757 & .19096 & .495 \\
& & From 11 and more & $.58556\left(^{*}\right)$ & .19096 & .012 \\
\multirow{4}{*}{ Reading } & From 6-10 & From 11 and more & .35799 & .18908 & .174 \\
& From 1-5 & From 6-10 & .47868 & .24319 & .151 \\
\multirow{3}{*}{ Writing } & & From 11 and more & $.72044\left(^{*}\right)$ & .24319 & .016 \\
& From 6-10 & From 11 and more & .2176 & .24079 & .606 \\
& From 1-5 & From 6-10 & .46282 & .24160 & .167 \\
Improvement & & From 11 and more & $.64872\left(^{*}\right)$ & .24160 & .032 \\
& From 6-10 & From 11 and more & .18590 & .23922 & .740 \\
& From 1-5 & From 6-10 & .32826 & .19071 & .234 \\
& & From 11 and more & $.58723\left(^{*}\right)$ & .19071 & .012 \\
& From 6-10 & From 11 and more & .25897 & .18884 & .395 \\
\hline
\end{tabular}

* The mean difference is significant at the .05 level. 
Post comparisons showed that teachers with (1-5) years experience with the mean (Speaking Mean=3.99, Reading Mean=3.87, Writing Mean=3.87, and the total of skills Improvement Mean=3.90) are higher than teachers with 11 years of experience and more with the mean (Speaking Mean=3.41, Reading Mean=3.15, Writing Mean=3.22, and the total of skills Improvement Mean=3.31) regarding the impact of SNS on Improving Arabic Language skills acquisition., and there are no statistical differences between the teachers' means of (1-5) vs.(11and more) and (6-10) vs. (11 and more).

To assure the relationship between experience years and the SNS impact on improving Arabic Language acquisition, Pearson's correlation was conducted as shown in the following table:

Table 10. Relationship between teachers experience and impact of SNS

\begin{tabular}{llll}
\hline Impact & & Pearson correlation & Sig \\
\hline Improving skills & Listening & -0.128 & .268 \\
& Speaking & $-0.336^{* *}$ & .003 \\
& Reading & $-0.324 * *$ & .004 \\
& Writing & $-0.296^{* *}$ & .009 \\
Total of impact on improving & $-0.337 * *$ & .003
\end{tabular}

It appears from Pearson's correlation that there is no significant relationship between SNS impact on improving students' Arabic Language skills according to teachers' experiences, but there is a negative relationship between Listening, Speaking, and Reading skills, and the total of SNS impact on improving them. Thus, it can be concluded that: more less experienced teachers considered that SNS has an impact on improving Arabic Language acquisition. This result points that younger teachers have a better knowledge of using digital technologies more than older teachers who have a very long experience.

Question 2: What are the strengths of SNS which improved Arabic Language acquisition for the students of higher elementary and secondary stages from their teachers' experiences?

The analysis of One sample t-test with $(\mathrm{df}=76)$ were used to determine the strengths of SNS in improving Arabic Language acquisition at the crucial score of upper bound of impact degree (see Table 4):

Table 11. Results of one sample t-test for the strengths of SNS

\begin{tabular}{lllllllll}
\hline Skills & Mean & SD & Rank & $\begin{array}{l}\text { Strength } \\
\text { degree }\end{array}$ & $\begin{array}{l}\text { Crucial } \\
\text { score }\end{array}$ & T value & Sig & Strenght degree \\
\hline Arabic Sites & 4.18 & 0.82 & 5 & High & 3.40 & 8.338 & $.000(\mathrm{a})$ & High \\
Classical Language & 4.14 & 0.74 & 7 & High & & 8.829 & $.000(\mathrm{a})$ & High \\
Writing Tools & 4.18 & 0.81 & 5 & High & & 8.505 & $.000(\mathrm{a})$ & High \\
Multimedia & 4.26 & 0.88 & 4 & Very High & 4.20 & 0.596 & .553 & High \\
Reading Activities & 4.30 & 0.83 & 2 & Very High & & 1.046 & .299 & High \\
Original Resources & 4.31 & 0.69 & 1 & Very High & & 1.414 & .161 & High \\
Virtual Reality & 4.30 & 0.65 & 2 & Very High & & 1.332 & .487 & High \\
Strengths & 4.24 & 0.52 & & Very High & 4.20 & 0.668 & .506 & High \\
\hline
\end{tabular}

One sample t-test revealed that there are statistical differences at $(\alpha \leq 0.05)$ between the observed means of Arabic Sites, Classical Language, and Writing Tools and the crucial score (3.40), which means that the degrees are in the High degree of strengths in Improving Arabic Language skills acquisition. On the other hand, there are no statistical differences between the observed means of Multimedia, Reading Activities, Original Resources, Virtual Reality, and total of Strength and the crucial score (4.20), therefore the degrees are High.

When ranking the items that strengthen improving Arabic Language acquisition, the original resources that is the availability of learning resources and content suitable for Arabic Language gained the highest degree with a mean $=4.32$, and each of Virtual Reality that is the availability of opportunities in SNSs to practice the four skills (reading, writing, listening, and speaking) of Arabic Language along with Reading Activities that is the availability of pages and accounts in SNSs that encourage reading through different activities and ways with a mean $=4.30$ have the second rank. On the contrary, Classical Language that is the availability of famous scientists, authors, and writers who 
speak and write in classical Arabic Language at SNSs, gets the lowest degree of availability as a means of strengthening SNS.

Two sample t-test was used to determine the advantages of SNS that strengthen improving Arabic Language acquisition according to teachers' experience in relation to variables: Gender of students, Stage and Qualification of teachers as shown in Table 12:

Table 12. Results of two sample t-test (DF=75) for the strength of SNS

\begin{tabular}{lllllll}
\hline Variables & & $\mathrm{N}$ & Mean & $\mathrm{SD}$ & $\mathrm{T}$ & $\mathrm{Sig}$ \\
\hline Gender & Male & 38 & 4.12 & 0.52 & 2.036 &, 045 \\
& Female & 39 & 4.36 & 0.50 & & \\
Stage & Elementary & 41 & 4.10 & 0.45 & 2.30 & .017 \\
& Secondary & 36 & 4.37 & 0.54 & & \\
Qualification & BSC & 56 & 4.32 & 0.51 & 2.187 & .032 \\
& MasterlPhD & 21 & 4.03 & 0.48 & & \\
Total & & 77 & 4.30 & 0.65 & & \\
\hline
\end{tabular}

Out of Table 12, two sample t-tests revealed:

According to teachers' experience, it appears that strengths of SNS improved male and female students of Arabic Language acquisition. Two sample t-test revealed that there are significant differences at $(\alpha \leq 0.05)$ between Male and Female students according to teachers' experience regarding the strengths of SNS in improving Arabic Language skills acquisition due to Gender, Stage, and Qualification for the benefit of Female, Secondary, and BSC holders.

When comparing these results with results of SNS Impact (see table 6), it appears that there is a consistency between those results, where Female, Elementary, and BSC teachers gave a high degree of the Impact as well as the Strengths.

Those findings show that Arabic teachers believe that SNSs have a high degree of Strengths in improving the acquisition of Arabic Language skills according to their experience. Based on these results, it appears that SNSs:

a) served in presenting information and knowledge about Arabic Language,

b) helped the students by presenting famous scientists, authors, and writers who speak and write in classical Arabic Language,

c) created proper tools for encouraging any user to practice writing and publishing on those sites,

d) provided recorded written texts which can be listened to in classical Arabic Language,

e) encouraged reading through different activities and ways,

f) provided learning resources and content suitable for Arabic Language, and

g) gave opportunities to practice the for skills (reading, writing, listening, and speaking) of Arabic Language .

To understand the teachers' years of experience differences in considering the strengths of SNS that improved Arabic Language skills, One-way ANOVA is the means to measure these differences.

Table 13. Means and SD of SNS strengths according to years of experience

\begin{tabular}{lllll}
\hline Experience & Mean & SD & Strengths Degree & Rank \\
\hline 1-5 years. N=25 & 4.44 & 0.58 & Very High & 1 \\
6-10 years. N=26 & 4.24 & 0.48 & Very High & 2 \\
11 years and more. N=26 & 4.04 & 0.43 & High & 3 \\
Total. N=77 & 4.24 & 0.52 & Very High & \\
\hline
\end{tabular}

Table 13 shows the obvious means of SNS strength of improving Arabic Language skills according to teachers' years of experience. One-way ANOVA was conducted to examine the differences between those means as shown in Table 14: differences. 
Table 14. One-way ANOVA of SNS strengthsaccording to years of experience

\begin{tabular}{lllllll}
\hline Source of Variance & Sum of Squares & df & Mean Square & F & Sig. \\
\hline Experience & Between Groups & 1.999 & 2 & 1.000 & 4.041 & .022 \\
& Within Groups & 18.304 & 74 & 0.247 & & \\
Total & 20.304 & 76 & & &
\end{tabular}

Results of the ANOVA revealed significant differences at $\alpha \leq 0.05$ between the means of years of experience of SNS strengths in improving Arabic Language skills acquisition. Thus, Arabic language teachers in Ma'an Directorate differ according to their experience.

Scheffe's Post multiple comparison was conducted to assure those differences as shown in Table 15:

Table 15. Results of Scheffe's multiple comparison for experience

\begin{tabular}{llllll}
\hline Dependdent variable & (I) Experince & (J) Experience & $(\mathrm{I}-\mathrm{J})$ & Std. Error & Sig \\
\hline Strengths & From 1-5 & From 6-10 & .19824 & .13931 & .368 \\
& & From 11 and more & $.39604\left(^{*}\right)$ & .13931 & .022 \\
& From 6-10 & From 11 and more & .19780 & .13794 & .363 \\
\hline
\end{tabular}

* The mean difference is significant at the .05 level.

Post comparisons showed that teachers with (1-5) years experience with the Mean=4.44 is higher than teachers having 11 years of experience or more with the Mean=4.04 regarding the strength of SNS in Improving Arabic Language skills acquisition, and there are no statistical differences between the teachers' means of (6-10) vs. (11 and more). Pearson's correlation (-.314) was significant at $(\alpha=0.01)$ level, the following figure shows the distribution strength of SNS according to teachers' experiences:

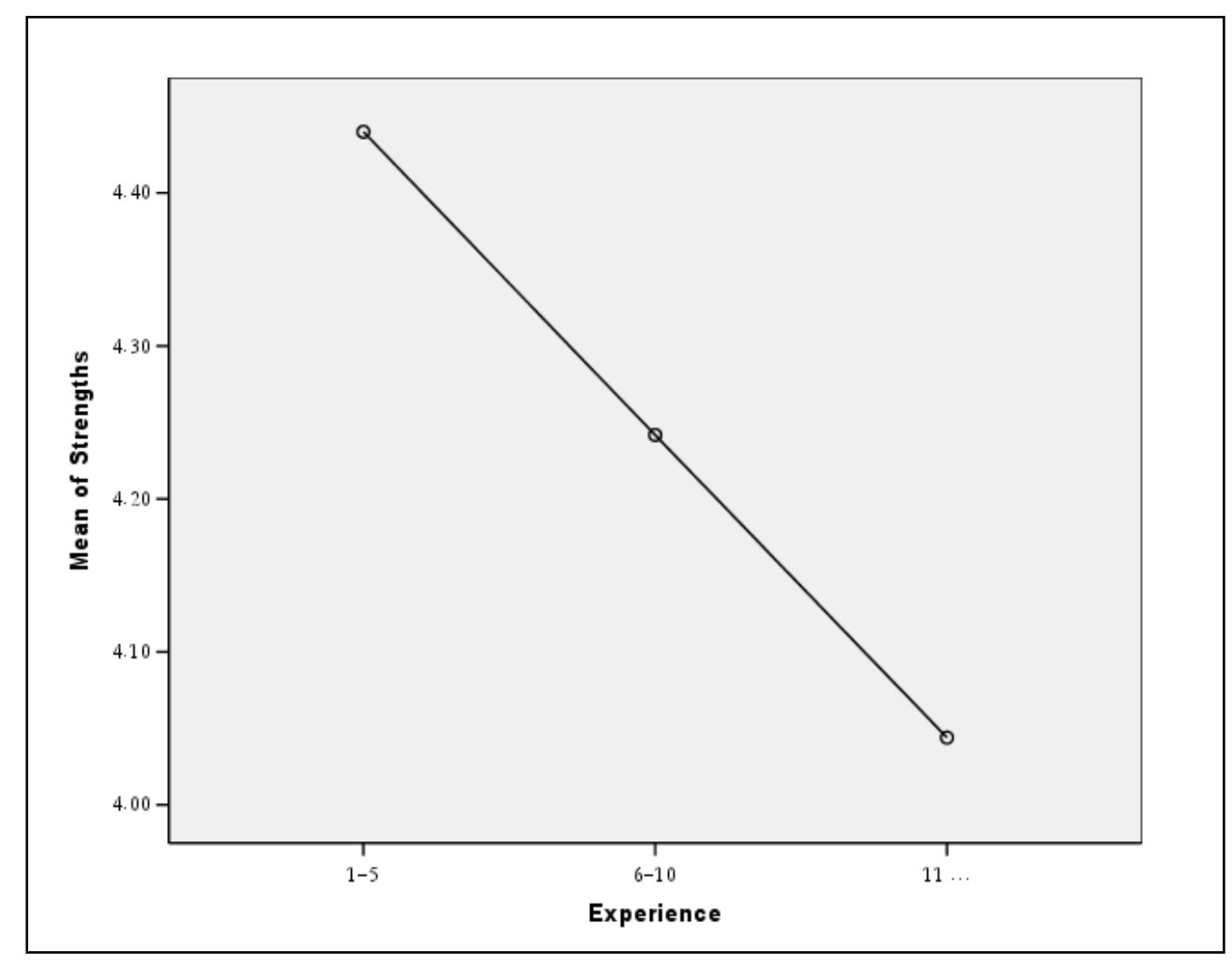

Figure 1. Histogram of relationship between SNSlstrengths and teachers' experience

Correlation shows that the degree of SNS Strength in Arabic language skills acquisition differs based on teachers' experience. In other words, low-experienced teachers believe in the high strength of SNS while more-experienced teachers perceive SNS as having low strengths. This result can be attributed to the fact that the less teaching 
experiences that younger teachers have the better experience in using SNS they gain than elder teachers with longer teaching experiences.

Question 3: What are the weaknesses of SNS which prevent improving Arabic Language acquisition for the students of higher and secondary stages based on their teachers' experience?

The analysis of One sample t-test with $(\mathrm{df}=76)$ were used to determine the weaknesses of SNS on improving Arabic Language acquisition at the crucial score of upper bound of impact degree (see Table 4):

Table 16. Resutls of one sample t-test for the weaknesses of SNS

\begin{tabular}{lllllllll}
\hline Skills & Mean & SD & Rank & $\begin{array}{l}\text { Improving } \\
\text { degree }\end{array}$ & $\begin{array}{l}\text { Crucial } \\
\text { score }\end{array}$ & $\begin{array}{l}\text { T } \\
\text { value }\end{array}$ & Sig & $\begin{array}{l}\text { Improving } \\
\text { degree }\end{array}$ \\
\hline Colloquial Language & 4.45 & 0.66 & 4 & Very High & 4.20 & 3.385 & .001 & Very high \\
Arabizi & 4.38 & 0.71 & 6 & Very High & & 2.190 & .032 & Very high \\
Mixed language & 4.08 & 0.90 & 11 & High & 3.40 & 6.611 & $.000($ a) & High \\
Weak partners & 4.09 & 0.95 & 10 & High & 3.40 & 6.392 & $.000($ a) & High \\
Common mistakes & 4.19 & 0.96 & 9 & High & & 263 & .000 & High \\
Spelling mistakes & 4.55 & 0.68 & 1 & Very High & 4.20 & 4.461 & .000 & Very High \\
Grammatical mistakes & 4.51 & 0.79 & 2 & Very High & & 3.411 & .001 & Very High \\
Editing responsibly & 4.43 & 0.88 & 5 & Very High & & 2.279 & .025 & Very High \\
Electronic writing & 4.47 & 0.82 & 3 & Very High & & 2.861 & .005 & Very High \\
Distraction attention & 4.27 & 0.90 & 8 & Very High & & 0.711 & .479 & High \\
Weaknesses & 4.36 & 0.84 & 7 & Very High & 3.40 & 1.706 & .092 & High \\
\hline
\end{tabular}

One sample t-test revealed that there aren't significant differences at $\alpha \leq 0.05$ between the mean of Listening (3.55), Reading (3.47), and Writing (3.49) and the crucial score (3.40) which represents the upper bound of Medium degree. Thus, the impact of SNS on improving these skills is medium. On the contrary, there are significant. Although one sample t-test revealed that there are statistical differences at $(\alpha \leq 0.05)$ between the observed means Colloquial Language, Arabezee, Spelling Mistakes, Grammatical Mistakes, Editing Responsibly, Electronic Writing, and the overall of Weaknesses and the crucial score (4.20), which means that the degrees of weaknesses are Very High with regard to weakening the acquisition of Arabic Language skills. Moreover, there are no statistical differences between the observed means of Eloquence Vs. Intellectuality and Attention Distraction with the crucial score (3.40) which means that those weaknesses are of a High Degree. When comparing factors of Mixed Language, Weak Partners, and Common Writing with the crucial score (3.40), t-test showed statistical differences, therefore those weaknesses are also of a High Degree.

When ranking the items of SNS that weaken Arabic Language acquisition, the spelling mistakes: The spread of spelling and linguistic mistakes in SNS gets the highest degree with a mean $=4.55$, while Mixed Languages: Mixing between Arabic and other foreign languages with a mean $=4.08$ has the lowest degree with a mean $=4.08$ though it still in a high degree of weakness.

Two sample t-test was used to determine the disadvantages of SNS that weaken improving Arabic Language acquisition according to teachers' experience in relation to variables: Gender of students, Stage and Qualification of teachers as shown in Table 17:

Table 17. Results of swo sample t-test $(\mathrm{DF}=75)$ for the weaknesses of SNS

\begin{tabular}{lllllll}
\hline Variables & & $\mathrm{N}$ & Mean & SD & $\mathrm{T}$ & $\mathrm{Sig}$ \\
\hline Gender & Male & 38 & 4.17 & 0.56 & 2.820 &, 006 \\
& Female & 39 & 4.52 & 0.52 & & \\
Stage & Elementary & 41 & 4.34 & 0.53 & 0.002 & .998 \\
& Secondary & 36 & 4.34 & 0.61 & & \\
Qualification & BSC & 56 & 4.10 & 0.53 & 1.725 & .089 \\
& MasterlPhD & 21 & 4.16 & 0.62 & & \\
Total & & 77 & 4.34 & 0.57 & & \\
\hline
\end{tabular}


Out of Table 17, two sample t-tests revealed:

There are significant differences at $(\alpha \leq 0.05)$ between Male and Female students according to teachers' experience with regard to the disadvantages of SNS in weakening Arabic Language skills acquisition due to Gender only for the benefit of Female, whereas Stage and Qualification do not differ.

Those findings show that Arabic teachers believe that SNSs have a high degree of disadvantages that weaken the acquisition of Arabic Language skills according to the teachers' experience. Based on these results, it appears that SNSs Prevalence includes different factors: colloquial language, Arabized English, mixed Arabic and other foreign languages, Partners whose language skills are weak, Common Writing, Spelling Mistakes, Grammatical Mistakes, lack of correcting, editing, or revising processes, Using keyboards to type which weakens students' Arabic handwriting skills, Scripts are linguistically eloquent but intellectually weak, distracting students' attention from what is useful and wastes their time.

To understand the teachers' years of experience differences in considering the weaknesses of SNS that prevent improvement of Arabic Language skills, One-way ANOVA is used to measure differences.

Table 18. Means and SD of SNS weaknesses according to years of experience

\begin{tabular}{lllll}
\hline Experience & Mean & SD & Strengths Degree & Rank \\
\hline 1-5 years. N=25 & 4.50 & 0.43 & Very High & 1 \\
6-10 years. N=26 & 4.20 & 0.67 & High & 3 \\
11 years and more. N=26 & 4.34 & 0.54 & Very High & 2 \\
Total. N=77 & 4.34 & 0.57 & Very High &
\end{tabular}

Table 18 shows the obvious means of SNS weaknesses that prevent improvement of Arabic Language skills acquisition according to teachers' years of experience. One-way ANOVA was conducted to examine the differences between those means as shown in Table 19:

Table 19. One-way ANOVA of SNS strengthsaccording to years of experience

\begin{tabular}{lllllll}
\hline Source of Variance & Sum of Squares & df & Mean Square & F & Sig. \\
\hline Experience & Between Groups & 1.165 & 2 & 0.583 & 1.866 & .162 \\
& Within Groups & 23.109 & 74 & 0.312 & & \\
\multirow{2}{*}{ Total } & 24.275 & 76 & & &
\end{tabular}

Results of the ANOVA revealed no significant differences at $(\alpha \leq 0.05)$ between the means of experience years of SNS weaknesses in improving Arabic Language skills acquisition. Thus, Arabic language teachers in Ma'an Directorate do not differ according to their experience.

Findings of the study are very consistent with the findings of Bazarah (2016) study. This study revealed that SNS impact and strengths show a high degree with regard to improving Arabic Language acquisition. However, there are still (11) disadvantages that may weaken both elementary and secondary students' Arabic Language acquisition. These disadvantaged are perceived as having a very high degree according to teachers' experience.

\section{Conclusion and Recommendations}

Based on teachers' experience, this study revealed a high degree of impact and a very high degree of both strengths and weaknesses of SNS on Arabic language acquisition among the students of elementary and secondary schools in Ma'an. These findings have implications for exert efforts to use SNS as an effective type of e-learning.

The results of this descriptive study help to clarify the existence of SNS uses in learning and teaching among Jordanian students because of the availability of internet access in lower prices through mobiles and different devices in Jordan even for children. There have to be more workshops to overcome weaknesses in some SNSs. Policy makers can take advantage of technology and direct teachers to take advantage of SNS by using it in learning and teaching situations and show them how to overcome weaknesses of SNS related to Arabic Language Acquisition. 


\section{References}

Abu-Omar, Reema. (2014). The Impact of using Inquiry and Brainstorming Strategies in Improving Reading and Writing Skills among Lower Primary Stage Students in Jordan, (Unpublished master's thesis)., Islamic Sciences and Education University. Jordan.

Al Doghmi, A., Al-Shalabi, H., Jwaifell,M. , Andraws, S., Awajan, A., \& Alrabea, A. I.(2013).The academic use of social networks among university students in Jordan. International Journal of Computer Science Issues, 10(5), 134-141.

Al-Harbi, Sarah \& Alshumaimeri, Yousif. (2016) The flipped classroom impact in grammar class on EFL Saudi secondary school students' performance and attitudes. English Language Teaching, 9(10), 60-80. https://doi.org/10.5539/elt.v9n10p60

AL Omosh, Sahar. (2018). The reality of using Arabic language teachers of the Internet in Al Mafraq Governorate In the implementation of extracurricular activities in the light of Some Variables, (Unpublished master's thesis)., Al al-Bayt University. Jordan.

Al-Sarhan, Jamilah. (2012). The Status of The Arabic Language Teachers Usage of the Internet in Teaching in the Governorate of Mafraq and their Attitudes Toward it, (Unpublished master's thesis)., Al al-Bayt University. Jordan.

Bazarah, Mariam. (2015). The Relationship between Social Network Sites and Arabic Language Skills Acquisition among Secondary Stage Female Students from Arabic Language Teachers Point View Researcher. (Unpublished master's thesis)., Creative Sciences University. UAE.

Bsharah, Muwafaq., Gasaymeh, Al-Mothana., and Bani Abdekrahman., Mahmoud. (2014). The Relationship between The Use of Social Networking Sites (SNS) and Perveived Level of Social Intelligence among Jordanian University Students: the Case of Facebook. International Journal of Psychological Studies, 6(3), 1-12. https://doi.org/10.5539/ijps.v6n3p1

Boyd, D. M, Ellison, N. B. (2007). Social network sites: Definition, history, and scholarship. Journal of Computer-Mediated Communication, 13(1), article 11. https://doi.org/10.1111/j.1083-6101.2007.00393.x

Drouin, M. A. (2011). College student's text messaging, use of textese and literacy skills. Journal of Computer Assisted Learning, 27, 67-65. https://doi.org/10.1111/j.1365-2729.2010.00399.x

Jwaifell, M., Al-Shalabi, H., Andraws, S., Awajan, A., \& Alrabea, A. (2013). The intensity of social networks group use among the students of Jordanian universities. Global Journal of Computer Science and Technology Network, Web \& Security, 13(2), 1-8.

Kwon, Ohbyung and Wen Yixing. (2009). An empirical study of the factors affecting social network service use. Computer in Human Behavior, 26(2010), 254-263. Available at: http://research.ecstu.com/km/efile/fb/factor_net_service.pdf. https://doi.org/10.1016/j.chb.2009.04.011

Ministry of Education in Jordan. (2013) The Frame of Arabic Language Outcomes and Goals for Primary and Secondary Stages. Curriculum and Textbooks Directorate. Available at: http://www.moe.gov.jo. 